\title{
Hepatitis virus infection and liver disease in injecting drug users who died suddenly
}

\author{
E A B McCruden, K J Hillan, I C McKay, M T Cassidy, J C Clark
}

\begin{abstract}
Aim-To determine the extent of liver damage resulting from infection with hepatitis B, C and D viruses (HBV, HCV and $H D V$ ) in intravenous drug users (IDUs).

Methods-Liver sections taken at necropsy performed to investigate the cause of sudden death in 48 IDUs were scored for necroinflammatory activity and fibrosis. Evidence of infection was by detection of viral antibodies in serum, hepatitis B surface antigen (HBsAg) and HCV RNA by reverse transcriptionpolymerase chain reaction (RT-PCR).

Results-Evidence of $\mathrm{HCV}$ infection was present in $43(90 \%)$ of 48 serum samples. Six (12\%) HBsAg positive serum samples had markers indicative of chronic HBsAg carriage, including three with antibody directed against HDV. Evidence of past HBV infection was found in $27(69 \%)$ of 39 HBsAg negative serum samples. HIV was detected in one (2\%) of 48 samples. In five $(10 \%)$ of 48 samples there was no evidence of current or past infection with HCV, HBV or HIV. All 43 liver sections from HCV positive IDUs scored $\geqslant 1$ for necroinflammatory activity, whereas three IDUs without HCV scored 0 . Scores for stage of fibrosis were $\geqslant 1$ in $15(35 \%)$ of 43 and zero of five IDUs, respectively. Fibrosis scores of $\geqslant 3$ were seen only in three IDUs positive for $\mathrm{HBV}, \mathrm{HDV}$ and $\mathrm{HCV}$. Conclusion-Inflammatory activity in the liver is present in a high proportion of IDUs in Glasgow and is strongly associated with HCV infection. Severe chronic liver damage was limited to HBsAg carriers superinfected with HDV and HCV. (F Clin Pathol 1996;49:552-555)
\end{abstract}

Keywords: intravenous drug users, HBV, HCV, HDV, liver damage, inflammatory activity.

Pathology,

Western Infirmary

K J Hillan

Department of Immunology,

University of Glasgow,

I C McKay

Department of Forensic Medicine M T Cassidy

J C Clark

Correspondence to: Dr Elizabeth McCruden, Institute of Virology, Church Street,

Glasgow G11 5JR.

Accepted for publication 21 March 1996 curred in recent years in intravenous drug users in Glasgow. In 1985 only three postmor- tem blood samples from intravenous drug users were referred for screening for HIV and hepatitis B surface antigen (HBsAg) prior to necropsy, but this figure increased until 1992 when 77 such samples were received. The cur- in rent study was carried out to establish the prevalence of infection with hepatitis B (HBV), $\mathrm{C}$ and $\mathrm{D}$ (HDV) and HIV, and to correlate liver histology with the serological findings.

\section{Methods}

Serum from 148 suspected intravenous drug users had been tested by the Institute of Virol- of ogy prior to necropsy between 1985 and 1992. N Liver specimens taken at necropsy were $\frac{\circ}{J}$ available for review from 57 . Sufficient serum $\vec{c}$ remained for further serological tests in 49 . In one case postmortem autolysis prevented $\rightarrow$ interpretation of liver sections. Therefore, comparison of hepatic histology with serological findings from 48 intravenous drug users (39 men and nine women; mean age 27 years, range 18-43 years) is the subject of this study. All 48 subjects were considered to be or have been regular intravenous drug users on the $\varrho$ basis of all the evidence available to the $\overrightarrow{0}$ pathologist at the time of necropsy. Permission for the study was granted by the Procurator Fiscal in Glasgow.

The cause of death on the necropsy report $\frac{8}{0}$ was drug intoxication in 34 subjects. Other causes of death were hanging (two subjects), stabbing, congenital heart disease, hypertensive heart disease, myocardial fibrosis, myocarditis, hernia of small bowel, bacterial endocar- 음 ditis, bronchitis and cirrhosis of liver, polycystic $\frac{7}{O}$ kidneys, and epileptiform seizure. Cause of death was not ascertained in one subject and $\stackrel{N}{\circ}$ reports were not available for two. Drugs $N$ detected postmortem were morphine $(n=24)$, స్ట benzodiazepines $(n=23)$, ethyl alcohol ( $n$ O $=17)$, paracetamol $(n=5)$, cannabis $(n=2)$, and diconal, prothiaden, chloral hydrate, cy- $\frac{\Gamma}{\Phi}$ clizine, and methadone ( $\mathrm{n}=1$ for each drug). $\stackrel{?}{+}$ More than one drug was present in 30 subjects.

All serum samples were tested for current or past infection with HCV, HBV or HIV by $\stackrel{\Phi}{\oplus}$ assays for antibodies directed against these $\stackrel{\mathbb{Q}}{\Omega}$ agents and for $\mathrm{HBsAg}$. In those subjects positive for the latter, tests for the stage and $\delta$ infectivity of the HBV infection and for superinfection with HDV were performed. Reverse transcription-polymerase chain reaction (RTPCR) for HCV RNA was carried out on all serum samples for which sufficient sample remained.

Serum samples were examined for antibodies directed against HCV by a second generation enzyme linked immunosorbent assay

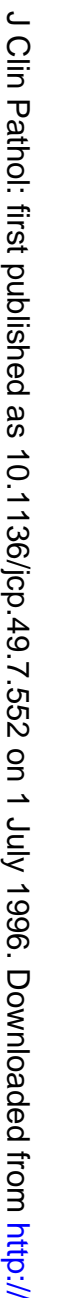


Table 1 Histological activity index

\begin{tabular}{|c|c|c|}
\hline Score & Inflammatory activity & Fibrosis \\
\hline 0 & None/minimal & None \\
\hline 1 & $\begin{array}{l}\text { Portal inflammation with or without } \\
\text { lobular activity }\end{array}$ & Enlarged fibrotic portal tracts \\
\hline 2 & $\begin{array}{l}\text { Portal inflammation with focal parenchymal } \\
\text { cell necrosis }\end{array}$ & $\begin{array}{l}\text { Periportal or portal-portal septa, } \\
\text { architecture intact }\end{array}$ \\
\hline 3 & $\begin{array}{l}\text { Portal inflammation with severe } \\
\text { parenchymal necrosis }\end{array}$ & $\begin{array}{l}\text { Fibrosis, architectural distortion, } \\
\text { no cirrhosis }\end{array}$ \\
\hline 4 & Damage including bridging necrosis & Cirrhosis \\
\hline
\end{tabular}

Table 2 Scores for necroinflammatory activity in liver sections related to serological evidence of infection with $H B V, C$ and $D$

\begin{tabular}{|c|c|c|c|c|c|}
\hline \multirow[b]{2}{*}{ Serological variables } & \multicolumn{4}{|c|}{ Necroinflammatory activity score } & \multirow[b]{2}{*}{ Total } \\
\hline & 0 & 1 & 2 & 3 & \\
\hline HBsAg + /anti-HDV + & 0 & 0 & 1 & 2 & $3(7 \%)$ \\
\hline HBsAg + /anti-HDV - & 0 & 1 & 2 & 0 & $3(7 \%)$ \\
\hline HbsAg - /previous HBV + & 0 & 11 & 13 & 3 & $27(59 \%)$ \\
\hline HBsAg - /previous HBV - & 0 & 1 & 5 & 1 & $7(15 \%) \ddagger$ \\
\hline HBsAg - /previous HBV unknown & 0 & 0 & 3 & 0 & $3(7 \%)$ \\
\hline $\mathrm{HCV}+\star{ }^{\star}($ total $)$ & 0 & 13 & 24 & 6 & $43(93 \%)$ \\
\hline $\mathrm{HCV}-\dagger$ & 3 & 0 & 0 & 0 & $3(7 \%)$ \\
\hline Total & $3(7 \%)$ & $13(27 \%)$ & $24(52 \%)$ & $6(13 \%)$ & 46 \\
\hline
\end{tabular}

Numbers in parentheses show the percentage (rounded up) of subjects with that result.

$\star$ Positive for HCV RNA or anti-HCV, or both

†Negative for both HCV RNA and anti-HCV.

‡Includes single HIV positive subject.

(ELISA) (Abbott Laboratories, Chicago, Illinois, USA) and by recombinant immunoblot (RIBA-2, Ortho Diagnostic Systems, High Wycombe, UK). HBsAg and HBeAg, antibodies directed against hepatitis $\mathrm{B}$ core (total anti$\mathrm{HBc}$, IgM anti-HBc), surface (anti-HBs) and e antigens (anti-HBe) were detected by ELISA or RIA (Abbott Laboratories). Antibodies directed against HDV were detected by ELISA (Organon Technika Cambridge, UK). Antibodies directed against HIV were detected by ELISA (Murex Ltd, Dartford, London, UK, or Abbott Laboratories). Confirmation of the HIV ELISA positive result was by western blot (performed by the Regional Virus Laboratory, Ruchill Hospital, Glasgow). HBsAg and antiHIV tests were performed at the time of death and, if the sample was HBsAg positive, tests for total and IgM anti-HBc, $\mathrm{HBeAg}$ and anti-HBe were carried out. All other assays were performed on serum which had been stored at $-20^{\circ} \mathrm{C}$.

RNA extraction and RT-PCR of the HCV 5' non-coding region were performed on $100 \mu \mathrm{l}$ aliquots of serum, as described previously. Briefly, RNA extracted using an acid guanidium thiocyanate method was precipitated with isopropanol followed by a phenol-chloroform extraction. RNA was reverse transcribed using Moloney murine leukaemia virus reverse transcriptase (Gibco-BRL, Gaithersburg, Maryland, USA) and primer ENCR2 (genome position -20 to -2$).^{5}$ Primers EPT1 $(-179$ to - 160) and ENCR2 were used in the first round of PCR, then $1 \mu \mathrm{l}$ of product was transferred to a second round PCR using primers EPT3 ( -142 to -125$)$ and NCR4 ( -52 to - 38). PCR conditions were as follows: 25 cycles at $94^{\circ} \mathrm{C}$ for 30 seconds, $55^{\circ} \mathrm{C}$ for $30 \mathrm{sec}-$ onds and $72^{\circ} \mathrm{C}$ for 90 seconds with Taq polymerase (Boehringer-Mannheim $\mathrm{GmbH}$,
Lewes, UK). PCR products, electrophoresed in a $2 \%$ agarose gel containing ethidium bromide, were photographed under ultraviolet light.

Livers were fixed in $10 \%$ buffered formalin and embedded in paraffin wax. Sections, $5 \mu \mathrm{m}$ thick, were cut consecutively from each block and stained with haematoxylin and eosin, Masson's trichrome, Gordon and Sweet's reticulin, Shikata's orcein, and by periodic acid Schiff with or without diastase. The liver sections were assessed for the histological features of $\mathrm{HCV}$ infection and scored using a histological activity index (table 1). Because of the autolytic changes observed in some livers, it was not always possible to score the inflammatory index as originally proposed by Scheuer. ${ }^{6}$ Scoring was therefore modified so that all livers in this study could be assessed.

The statistical significance of the association between virus infection and histological scores was assessed using Fisher's exact test.

\section{Results}

VIRAL SEROLOGY

Of the 48 serum samples, $41(83 \%)$ were $\mathrm{HCV}$ positive by ELISA. Thirty nine were also positive by RIBA 2, but insufficient serum remained in two. All anti-HCV negative serum samples were negative by RIBA 2. RT-PCR was positive in $17(41 \%)$ of 41 serum samples in which sufficient sample remained for testing. Two serum samples which were negative for anti-HCV were positive by RT-PCR.

Six $(12.5 \%)$ of 48 serum samples were $\mathrm{HBsAg}$ positive. All were negative for anti-HBc IgM antibody, indicating chronic carriage of $\mathrm{HBsAg}$. Only one was positive for $\mathrm{HBeAg}$; the other five were anti-HBe positive. Anti-HDV antibody was detected in three $(50 \%)$ of the six $\mathrm{HBsAg}$ positive serum samples; all three were anti-HBe positive. In $42 \mathrm{HBsAg}$ negative serum samples, both anti-HBc and anti-HBs were detected in 18, anti-HBc alone in six, anti-HBs alone in three, and neither anti-HBc nor anti-HBs in 12. Insufficient serum remained for either test in three subjects. Therefore, past infection with $\mathrm{HBV}$ was demonstrated in $27(69 \%)$ of $39 \mathrm{HBsAg}$ negative intravenous drug users. One $(2 \%)$ of the 48 specimens was positive for anti-HIV.

Tables 2 and 3 show the combined results of $\mathrm{HCV}$ and HBV testing. Of 33 serum samples with current or past evidence of $\mathrm{HBV}$ infection, $32(97 \%)$ were positive for anti-HCV. Six subjects positive for anti-HCV had no evidence of past exposure to HBV. The one HIV positive serum contained no anti-HCV, anti-HBc or anti-HBs, but was positive for $\mathrm{HCV}$ by RT-PCR. The second anti-HCV negative serum which was positive by RT-PCR had evidence of past HBV infection. Therefore, in this series, there was no subject with evidence of current or past $\mathrm{HBV}$ infection in the absence of $\mathrm{HCV}$ infection.

HISTOPATHOLOGY

Of the 48 livers were included in the study, two could not be scored for necroinflammatory 
Table 3 Stage of liver fibrosis, related to serological evidence of infection with $H B V, C$ and $D$

\begin{tabular}{|c|c|c|c|c|c|c|}
\hline \multirow[b]{2}{*}{ Serological variables } & \multicolumn{5}{|c|}{ Score for stage of fibrosis } & \multirow[b]{2}{*}{ Total } \\
\hline & 0 & 1 & 2 & 3 & 4 & \\
\hline \multicolumn{7}{|l|}{ HCV infected } \\
\hline HBsAg + /anti-HDV + & 0 & 0 & 0 & 1 & 2 & $3(6 \%)$ \\
\hline $\mathrm{HBsAg}+$ /anti-HDV - & 2 & 0 & 1 & 0 & 0 & $3(6 \%)$ \\
\hline HbsAg - /previous HBV + & 19 & 5 & 3 & 0 & 0 & $27(59 \%)$ \\
\hline HbsAg - /previous HBV - & 5 & 2 & 0 & 0 & 0 & $7(15 \%) \ddagger$ \\
\hline HbsAg - /previous HBV unknown & 2 & 0 & 1 & 0 & 0 & $3(6 \%)$ \\
\hline $\mathrm{HCV}+{ }^{\star}($ total $)$ & 28 & 7 & 5 & 1 & 2 & $43(93 \%)$ \\
\hline $\mathrm{HCV}-t$ & 5 & 0 & 0 & 0 & 0 & $5(10 \%)$ \\
\hline Total & $33(69 \%)$ & $7(15 \%)$ & $5(10 \%)$ & $1(2 \%)$ & $2(4 \%)$ & 48 \\
\hline
\end{tabular}

Numbers in parentheses show the percentage (rounded up) of subjects with that result.

^Positive for HCV RNA or anti-HCV, or both.

†Negative for both HCV RNA and anti-HCV.

¥Includes single HIV positive subject.

activity because of postmortem autolysis. It was possible to stage fibrosis in all livers.

Only five livers were histologically within normal limits although, in two of these, autolysis prevented the assessment of inflammatory infiltration. All remaining 43 livers showed abnormal liver histology, with a chronic inflammatory infiltrate present within at least some portal tracts. In many, the infiltrate was patchy, often varying considerably in intensity between portal tracts. Portal lymphoid follicles were observed in only two livers. In 13 subjects, lobular inflammation accompanied by parenchymal cell necrosis was noted; bridging necrosis was observed in six of these. Portal or periportal fibrosis, or both, was present in 15 subjects. In three of these, there was accompanying architectural distortion, which amounted to cirrhosis in two. Non-caseating granulomas were identified in two livers. Although no aetiological agent could be identified in either, they were presumed to be related to intravenous drug use. In none of the livers examined was there any evidence of toxic (including alcohol induced) damage.

\section{CORRELATION OF SEROLOGY WITH}

HISTOPATHOLOGY

Tables 2 and 3 show the relation between the serological results for hepatitis $B$ and $C$ and necroinflammatory activity and fibrosis scores, respectively. Subjects were considered to have $\mathrm{HCV}$ infection if their serum contained anti-HCV or HCV RNA, or both. All HCV infected livers had a necroinflammatory score of $\geqslant 1$ and fibrosis was seen in 15 (35\%) of 43 . None of the uninfected livers showed any inflammation or fibrosis. The association between $\mathrm{HCV}$ infection and inflammatory score was significant by Fisher's exact test $(p<$ 0.0001 for the whole study group; $p<0.008$ for the subset with no evidence of past or present $\mathrm{HBV}$ infection).

Considering livers from $\mathrm{HCV}$ positive intravenous drug users, there was nothing to indicate that either past or current $\mathrm{HBV}$ infection, in the absence of HDV superinfection, had any effect on the scores for necroinflammatory activity $(p=0.68)$ or fibrosis ( $p=$ 0.57 ). In contrast, the three livers from HDV superinfected carriers had either severe architectural distortion or cirrhosis, and had high scores of 2,3 and 3, respectively, for necroinflammatory activity.

\section{Discussion}

Serological evidence of infection with blood of borne viruses was common in this group of $N$ intravenous drug users who died suddenly. 을 HCV was the most prevalent with 43 (90\%) $\vec{c}$ serum samples containing HCV RNA or antiHCV. All six (12\%) HBsAg positive serum samples had markers indicative of chronic HBsAg carriage and three were superinfected with HDV. Evidence of past infection was found in $28(70 \%) \mathrm{HBsAg}$ negative serum samples available for testing. Anti-HIV was detected in one $(2 \%)$ sample. In only five $(10 \%)$ serum samples was there no evidence of current or past infection with $\mathrm{HCV}, \mathrm{HBV}$ or HIV. When an individual starts sharing needles in a group of drug users, he is more likely to be exposed to blood containing infectious $\mathrm{HCV}$ than HBV. As HCV RNA was detected ? in 17 of those that could be tested, a minimum rate of current infection is $41 \%$ in this population. The true rate was almost certainly higher as false negative RT-PCR results may have occurred as a result of postmortem degradation of RNA. Episodic viraemia can also $\frac{7}{0}$ occur. ${ }^{4}$ In contrast, six subjects were currently infectious for HBV but only one was HBeAg o positive. However, anti-HBe positive $\mathrm{HBsAg} N$ carriers are susceptible to and can transmit N HDV to other HBsAg positive subjects.

No community based studies of anti-HCV prevalence in intravenous drug users have been possible, similar to those in which anti-HIV testing has been carried out on saliva, ${ }^{8}$ as an anti-HCV assay of sufficient sensitivity is not $\frac{\vec{d}}{\mathbb{D}}$ available as yet. Retrospective testing of serum samples taken from intravenous drug users for $\mathbb{Q}$ other purposes will not represent a true community prevalence. However, anonymous 8 retrospective testing of 269 Glasgow serum samples submitted for anti-HIV testing, in which intravenous drug use was identified as a risk factor, demonstrated that $230(86 \%)$ were positive for anti-HCV and $70 \%$ for anti-HBc (Follett EAC, personal communication). The conclusion from this and other studies ${ }^{129}$ is that although the groups may not be representative of the entire intravenous drug 
user community, all show an extremely high prevalence of $\mathrm{HCV}$ infection, far higher than that of HBV.

Abnormal liver histology was closely related to serological evidence of $\mathrm{HCV}$ and $\mathrm{HDV}$ infection. The lack of abnormalities in the livers of intravenous drug users with no markers of $\mathrm{HBV}$ or $\mathrm{HCV}$ infection suggests that intravenous drug use with the substances injected in Glasgow does not, in itself, produce liver damage. This conclusion is supported in three of such subjects in which high levels of morphine or temazepam (both commonly injected substances in Glasgow) were found. A fourth subject with no detectable drugs was nevertheless said to have a "strong history" of prolonged drug use. No toxicological data were available for the fifth subject. The low prevalence of HIV infection in Glasgow intravenous drug users has been documented ${ }^{8}$ and facilitates the interpretation of liver damage induced by HBV, $\mathrm{C}$ and $\mathrm{D}$.

The most severe cases of liver damage were restricted to individuals with evidence of combined HBV, HCV and HDV infections. It has been previously estimated that there may be 70 such individuals in the Glasgow are ${ }^{10}$ and their future care will have implications for health care resources. The need for resources to treat the larger number of intravenous drug users with chronic $\mathrm{HCV}$ is harder to assess. All subjects with serological evidence of $\mathrm{HCV}$ infection had inflammatory changes in the liver and it seems likely that more severe disease will develop in time in a proportion of these subjects. ${ }^{11}$ The epidemic of intravenous drug use in the Glasgow area became widespread in the early 1980 s so most intravenous drug users will have become infected within the past 15 years. A study in the United States showed no increased mortality in mostly middle-aged patients with post transfusion acquired $\mathrm{HCV}$ over 20 years, ${ }^{12}$ but intravenous drug users in
Glasgow are infected with $\mathrm{HCV}$ in their teens and twenties. There was no evidence from our study that liver damage was more severe in $\mathrm{HCV}$ positive subjects where there was evidence of current or past infection with HBV.

In conclusion, of 48 intravenous drug users who died suddenly, HCV infection was found in $43(90 \%)$, current $\mathrm{HBV}$ in six $(11 \%)$ and $\mathrm{HIV}$ in one $(2 \%)$. Liver disease was mild in intravenous drug users with evidence of current $\mathrm{HCV}$ infection alone. Severe hepatic architectural distortion was seen only in those with concurrent $\mathrm{HBV}, \mathrm{D}$ and $\mathrm{C}$ infections. Supported in part by GGHB Research Support Group (ref. no
RSG/END/1993/D. We are grateful to Brian Batchelor and the RSG/END/1993/J). We are grateful to Brian Batchelor and the
MLSOs in the Diagnostic Laboratory for expert technical assistance and to Dr John Oliver for toxicology data.

1 Donahue JC, Nelson KE, Munoz A, Vlahov D, Rennie LL, Taylor $\mathrm{E}$, et al. Antibody to hepatitis $\mathrm{C}$ virus among cardiac surgery patients, homosexual men and intravenous drug surgery patients, homosexual men and intravenous d

2 Quaranta JF, Delaney SR, Alleman S, Cassuto, Dellamonica $P$, Allain JP. Prevalence of antibody to hepatitis $C$ virus (HCV) in HIV-1 infected patients (Nice SEROCO cohort). f Med Virol 1994;42:29-32.

3 Houghton M. Molecular biology of the hepatitis C viruses: implications for diagnosis, development and control of viral disease. Hepatology 1991;69:381-8.

4 McCruden EAB, Welch S, Batchelor B, Briggs JD. Hepatitis $C$ virus infection detected by antibody tests and the polymerase chain reaction as a cause of liver dysfunction in polymerase chain reaction as a cause of liver dysfunction in

5 Choo QL, Richman KH, Han JH. Genetic organisation and diversity of the hepatitis C virus. Proc Natl Acad Sci USA 1991;88:2451-5.

6 Scheuer PJ. Classification of chronic viral hepatitis: a need for reassessment. $\mathcal{F}$ Hepatol 1991;13:372-4.

7 Fisher RA. Statistical methods for research workers. 12th edn. London: Oliver and Boyd, 1954.

8 Covell R, Follett E, Coote I, Bloor M, Finlay A, Frischer M, et al. HIV testing among injecting drug users in Glasgow. $\mathcal{f}$ Infect 1993;26:27-31.

9 Kelen GD, Green GB, Purcell RH, Chan DW, Qaqish BF, Sivertson $\mathrm{MD}$, et al. Hepatitis $\mathrm{B}$ and hepatitis $\mathrm{C}$ in Sivertson MD, et al. Hepatitis B and hepatitis C in emergency depart

10 McCruden EAB, Follett EAC. Hepatitis delta virus infections in intravenous drug abusers with hepatitis B in the West of Scotland. $\mathcal{f}$ Med Virol 1989;29:59-62.

11 Kiyosawa K, Tanaka T, Sodeyama T, Furuta S. Natural history of hepatitis C. Intervirology 1994;37:101-7.

12 Seeff LB, Buskell-Bales Z, Wright EC, Durako SJ, Alter HJ, Iber FL, et al. Long-term mortality after transfusionassociated non-A, non-B hepatitis. $N$ Engl $f \mathrm{Med}$ 1992;327:1906-11. 